\title{
La muerte según Baruch Spinoza: aproximaciones a una noción problemática
}

\author{
DIANA COHEN \\ Facultad de Filosofía y Letras \\ Universidad de Buenos Aires \\ dianacohen@arnet.com.ar
}

\begin{abstract}
RESUMEN: En el marco de la Sustancia omniabarcadora, eje del pensamiento de Spinoza, la noción de muerte no está exenta de problemas. Si se la concibe como la destrucción del cuerpo, pareciera que dicha definición complica sustantivamente nuestra concepción de la muerte. Pues si tal como piensa Spinoza, la materia es energía imperecedera, ¿̇se puede hablar propiamente de aniquilación? Si se afirma, en cambio, que la muerte es la pérdida de la identidad personal, nos podemos preguntar qué se entiende por identidad cuando, leído literalmente, Spinoza nos presenta una única entidad plenamente real: la Sustancia. Y si tomamos en cuenta su doctrina de que hay algo del alma que no perece con el cuerpo y es eterno, la noción de muerte abre interrogantes metafísicos que parecen entrar en colisión con la segunda parte de la Ética, donde se ofrece una descripción puramente mecánica de la realidad. ${ }^{1}$
\end{abstract}

PALABRAS ClaVE: conatus, destrucción, identidad, individuo, muerte.

\section{I.¿UNA DEFINICIÓN GENÉTICA DE MUERTE?}

Si se espera que nuestro filósofo ofrezca una clásica y prolija definición del concepto de muerte, no es éste el caso. Como se sabe, en lugar de las tradicionales definiciones por género y diferencia específica, Spinoza emplea definiciones genéticas que siguen el modelo de pensar geométrico. $\mathrm{Al}$ procurar extrapolar la certidumbre de las ciencias exactas al campo de la metafísica, el autor de la Ethica ordine geometrico demonstrata se habría preguntado cómo hacen los geómetras para determinar si han alcanzado la definición real de una figura. Así descubre que un geómetra percibe esta certeza, en verdad, cuando es capaz él mismo de construir esa figura. Y esto es posible porque su definición es una regla de construcción, y de ella pueden deducirse todas las propiedades de la figura por construir. Se podría objetar que las definiciones estipulativas en general y, en este caso en particular, las definiciones geométricas, al ser nominales, lo son de términos. No obstante, en este tipo de definiciones, el definiens es una expresión que designa la causa que produce la realidad designada por el definiendum. Así se obtiene una definición real de la cosa, en la medida en que se conoce su causa próxima y

1 Agradezco la atenta lectura y las valiosas observaciones del doctor Atilano Domínguez, profesor de la Universidad de Castilla-La Mancha y presidente del Seminario Spinoza. 
el modo en que las propiedades de la cosa se siguen necesariamente de esta causa. Por ejemplo, cuando digo "entiendo por círculo una figura producida por un segmento de recta, uno de cuyos extremos es fijo y el otro móvil", explico aquello que entiendo por la palabra círculo (definición nominal), pero también describo la verdadera naturaleza de esta figura.

Análogamente al modelo geométrico, según cree Spinoza, sus definiciones metafísicas poseen alcance ontológico, pues también son definiciones de cosas, que describen propiamente a estas cosas como son en sí mismas. Ese ordine geometrico consiste, precisamente, en que el sistema spinoziano aspira a fundarse en estas definiciones genéticas. En lo que concierne al tema que nos ocupa, una vez descritas las condiciones de esta clase de definiciones se percibe inmediatamente que, para el filósofo, la muerte ha de presentar más de un problema. Si la condición de una definición genética es el conocimiento de su causa próxima, en el caso específico de la definición mencionada, no tenemos una idea clara y distinta de esa causa: el médico estima que ya sea el cese de la actividad cardiorrespiratoria, ya sea el del funcionamiento cerebral, se deben presuntivamente al factor $x$ o tal vez al factor $y$, y el juicio clínico se emite a partir de esta estimación. Su juicio, no obstante, posee un valor meramente probabilístico, y carece de la exactitud propia del juicio del geómetra cuando éste define el círculo. Por lo tanto, debido al valor relativo del juicio clínico, no podemos suponer en el médico el grado de certeza que predicamos del geómetra.

Esta ausencia de certeza no sólo vuelve problemática una definición apropiada de la noción de muerte, también afecta la determinación de cuáles son los procesos biológicos que indican unívocamente el pasaje de la condición de estar vivo a la de estar muerto. Hasta el momento, según parece, no hay un evento último, claramente definible, que nos indique la pérdida completa de vida: ¿es la ausencia de actividad cardiorrespiratoria?, ¿es el cese de las funciones cerebrales en conjunto?, ¿o sólo de las neocorticales? En la determinación de la muerte, ¿qué criterio ha de primar, el cardiopulmonar, el encefálico, el neocortical? ${ }^{2}$

Estas cuestiones conciernen no sólo a la calificación de los muertos, sino también a la de los vivos, en cuanto ponen en tela de juicio la identidad entre la noción de ser humano (en cuanto especie) y la de persona (inter-

2 Este debate científico de inmensas consecuencias prácticas aún no ha terminado: a la tradicional definición cardiopulmonar de muerte, le ha seguido la definición de muerte basada en la ausencia de actividad encefálica, y a ésta la definición basada en la ausencia de actividad de las funciones neocorticales del cerebro. Véase "A Definition of Irreversible Coma: Report of the Ad Hoc Committee of the Harvard Medical School to Examine the Definition of Brain Death", JAMA, vol. 205, no. 6, agosto 5, 1968, pp. 337-340. Reimpreso en The Right to Die: Definitions and Moral Perspectives, Melvin I. Urovsky y Philip E. Urovsky (comps.), Garland Publishing, Nueva York/Londres, 1996. 
pretada como entidad a la que se le pueden adscribir estados mentales). Pero además, hoy por hoy, ellas cobran cada vez una mayor relevancia en el campo de la ética aplicada a la medicina, en la medida en que una adecuada definición de muerte y una clarificación de la noción de persona autorizaría, entre otras cosas, a retirarle a un paciente un tratamiento de sostén vital o a extraer los órganos de un ser humano muerto para ser trasplantados en otro vivo.

En resumen, las discusiones actuales sobre estos temas giran en torno a dos cuestiones: la primera de ellas es la de cómo debemos definir la muerte. ¿Debemos hacerlo en términos puramente biológicos, de manera tal que pueda aplicarse a cualquier individuo vivo (por ejemplo, decir que se trata del cese irreversible de las funciones orgánicas)? ¿O debemos definirla, tal vez, centrándola en el concepto de persona (y si es así, identificarla con el cese de la personalidad en cuanto tal)?

La segunda de las cuestiones debatidas concierne al criterio para determinar la muerte de un ser humano. Por ejemplo, si definimos la muerte en términos puramente biológicos, el criterio de muerte se basará en la determinación del órgano o conjunto de órganos cuyo cese irreversible en sus funciones indique la pérdida de la vida. Si definimos la muerte, en cambio, centrándola en la segunda de las definiciones mencionadas, la del concepto de persona, el criterio consistirá en el establecimiento de aquellos procesos biológicos centrales en la vida humana y cuya pérdida indique que la persona ha dejado de existir.

Spinoza, según se verá, parece tomar posición acerca de estos problemas actualmente en debate: si viviera hoy, el autor de la Ética formaría parte de la vanguardia que defiende un criterio de muerte encefálica o neocortical. En efecto, tal como el filósofo parece sugerir, existen muchas clases de individuos que se consideran vivos cuando no lo están. En términos contemporáneos, el criterio de Spinoza es, curiosamente, demasiaso estricto: mientras se ha llegado a discutir si los anencefálicos o los comatosos irreversibles pueden ser considerados vivos, el filósofo piensa que la sola pérdida irreversible de la continuidad psicológica señala el pasaje entre la vida y la muerte. Pero sobre estos temas nos explayaremos más adelante.

Por el momento, baste con señalar que estas dificultades, por cierto, fueron vislumbradas por Spinoza, y prueba de ello es que el autor de la Ética no ofrece una definición acabada de muerte. Internándonos ya en la metafísica y en la epistemología de este filósofo, si la definición supone la idea verdadera de una cosa y si, en este sentido preciso con que Spinoza dota a este término, por "idea" Spinoza entiende todo modo del atributo Pensamiento producido por el entendimiento que posee su correlato en el atributo Extensión, entonces carecemos de una idea propiamente dicha de la muerte. Pese 
a esta imposibilidad de tener una idea de la muerte, Spinoza alude a ella valiéndose de una noción que - pese o, mejor aún, en virtud de carecer de un significado unívoco- puede rastrearse a todo lo largo de la Ética. Esta diversidad de menciones no debe, pues, sorprender: el sistema de Spinoza aspira a explicar los modos tanto en el orden de la duración (en su carácter de cosas físicas y orgánicas) como en el orden de la eternidad. En el marco del sistema expuesto en la Ética, esta multiplicidad de órdenes se traduce en una riqueza conceptual que obliga a examinar el fenómeno de la muerte desde tres perspectivas básicas que enumeramos a continuación: en primer lugar la muerte se define como la destrucción del cuerpo. En este caso, un individuo muere cuando sucumbe a la presión del ambiente y ya no puede conservar su existencia. En segundo lugar, la muerte se manifiesta como una pérdida de la identidad personal. En tercer lugar, la muerte sobreviene cuando una parte del alma deja de afirmar la existencia del cuerpo. Una vez examinadas dichas perspectivas, se indagarán las razones que habrían llevado a Spinoza a defender, curiosamente, una multiplicidad de sentidos de una noción que, paradójicamente, en el marco de su sistema carece de realidad esencial.

\section{LAS APROXIMACIONES SPINOZIANAS A LA MUERTE}

\section{La muerte biológica: la destrucción del cuerpo}

Entre los distintos criterios hoy discutidos mediante los cuales se aspira a definir la muerte, el criterio biológico señala que la muerte humana es la destrucción irreversible del bulbo raquídeo, en la medida en que éste coordina las funciones del organismo considerado como un todo integrado. Esto significa que el cese del funcionamiento de la corteza cerebral no es suficiente para que se produzca la muerte del individuo. ${ }^{3}$ Un individuo muere, entonces, cuando deja de funcionar integradamente. Esta perspectiva contemporánea, con ciertas modificaciones explicables por el mecanicismo que inunda su teoría, es anticipada por Spinoza. Así pues, de las distintas definiciones que Spinoza ofrece del concepto de muerte, una de las más precisas se encuentra en E5P23, ${ }^{4}$ donde se lee que la muerte es la destrucción del cuerpo. A ella también alude cuando afirma que esta

3 David Lamb, Death, Brain Death and Ethics, Croom Helm, Londres, 1985.

${ }^{4}$ Las citas se toman de Ética demostrada según el orden geométrico, trad. de Oscar Cohan, Fondo de Cultura Económica, México-Buenos Aires, 1977.

De acuerdo con el sistema usual de abreviaturas de las obras de Spinoza, los pasajes de sus obras se citarán del siguiente modo: TIE = Tractatus de intellectus emendatione. Los números de las secciones son de la edición de C.H. Bruder, Lipsiae, 1843-1846. CM= Cogitata metaphysica. $\mathrm{E}=$ Ethica ordine geometrico demonstrata . A continuación se especificarán: 1, 2, 3,.. antece- 
destrucción del cuerpo se produce "cuando sus partes se disponen de tal manera que adquieren unas respecto de otras diversa relación de movimiento y reposo" (E4P39S), más precisamente, cuando las partes que lo componen cambian tan radicalmente que finalmente se modifica el quantum total de energía que lo constituía como ese cuerpo. Es notorio que Spinoza comparte con esta perspectiva biológica contemporánea el concepto del cuerpo como entidad compleja y la prevalencia de las funciones integradas que lo constituyen como tal. Sin embargo, en lugar de considerar - tal como lo hace la biología contemporánea cuando se refiere a la muerte del cuerpo humano- a esta porción de la médula espinal como determinante de la coordinación entre los distintos órganos del cuerpo, Spinoza alude -en un lenguaje mecanicista- a cierta proporción que guardan las partes del cuerpo con vida. Cuando esta proporción se quiebra, piensa Spinoza, el organismo deja de funcionar como tal y el individuo muere. Se observa entonces que la función atribuida a esta proporción por Spinoza es delegada, en la ciencia contemporánea, en el bulbo raquídeo.

Según esta perspectiva a la que hemos dado en llamar su primera aproximación a la noción de muerte, nuestro filósofo se refiere a cualquier clase de individuo, no necesariamente humano. Y a diferencia del alcance que le otorga hoy la biología (que asigna este concepto de muerte, como es obvio, fundamentalmente al hombre y a ciertas especies animales), Spinoza lo extiende a todos los individuos, incluso a los que nosotros calificamos de inorgánicos.

Centrémonos, entonces, en el marco teórico de Spinoza: ¿cuáles son los factores que intervienen en este proceso que determina la destrucción de un cuerpo individual? Esta modificación, piensa el filósofo, es la resultante de dos factores complementarios: de la presión ejercida por otras cosas singulares sobre el individuo, por una parte; se sigue a modo de efecto que finalmente ese individuo no pueda conservarse como el individuo que era, por otra. Examinemos, pues, ambos factores en detalle. ${ }^{5}$

didos por $\mathrm{E}=$ los numerales se refieren a las partes de la obra. $\mathrm{Ax} .=$ axioma. $\mathrm{P}=$ proposición. Def. $=$ definición. $1,2,3, \ldots=$ se refieren a los axiomas, definiciones, proposiciones, etc. $\mathrm{D}$ precedido por $\mathrm{P}$ seguida de un numeral $=$ la demostración de la proposición. Cor. $=$ corolario. $\mathrm{S}=$ escolio Post. $=$ postulado Lem. $=$ lema. Exp. $=$ explicación. Ap. $=$ apéndice. A título de ejemplo: E4P39S: Ética, cuarta parte, proposición 39, escolio.

5 En "La mirada del gusano y el ojo de Dios: consideraciones acerca de los principios de individuación y de continuidad temporal en Spinoza", expuse la teoría física de Spinoza como punto de partida del análisis del individuo en su relación con la Sustancia (Materia, espacio y tiempo: de la filosofía natural a la física, L. Benítez y J.A. Robles (coords.), Facultad de Filosofía y Letras, División de Estudios de Posgrado, Universidad Nacional Autónoma de México, México, 1999, pp. 81-94). 
1.1 La presión del ambiente sobre el individuo concebido como un complejo homeostático

La definición de muerte como destrucción del cuerpo nos obliga a indagar, antes que nada, cómo caracteriza Spinoza los cuerpos en general. ${ }^{6} \mathrm{El}$ filósofo comienza la exposición de su teoría física afirmando que todos los cuerpos o se mueven, o están en reposo. Cabe advertir, pues, que el movimiento y el reposo constituyen un único modo infinito producido inmediatamente por el atributo de la Extensión y, respecto de los modos finitos, es la propiedad inherente a los cuerpos en general. Si el movimiento y el reposo es un único modo que constituye la materia común a todos los cuerpos, ¿cómo se distingue, entonces, un cuerpo de otro? Spinoza, en lo que concierne a aquello que le confiere a un cuerpo el carácter de entidad individual, comienza proponiendo un mecanismo externo de cohesión que se reduce a la presión mecánica que ejerce el medio sobre otro cuerpo en particular. Si dicha presión se ejerce dentro de los límites tolerados por el cuerpo afectado, esta presión produce la preservación estructural de este último.

¿Cómo se aplica este mecanismo al hombre? El filósofo expone su teoría del cuerpo humano en una serie de postulados, que no son sino una serie de contrastaciones empíricas. Allí declara que el cuerpo humano es un individuo, compuesto a su vez por una gran cantidad de individuos (E2P13Post.1), cada uno de los cuales es también compuesto (pensemos en los tejidos, los órganos, etcétera).

Esta escueta referencia al individuo humano cede su lugar casi inmediatamente a la teoría general de los cuerpos físicos a la que Spinoza retorna y en el marco de la cual ha de analizarse cualquier individuo. La razón de esta subordinación del individuo humano a la generalidad de los cuerpos encuentra su explicación cuando Spinoza declara que, al igual que todos los cuerpos singulares, también los individuos que componen el cuerpo humano "todos juntos componen un solo cuerpo o individuo que se distingue de los demás por esta unión de cuerpos" (E2P13Def.). Pero como las muñecas rusas, estos individuos o cuerpos progresivamente más complejos -incluidos los individuos humanos - se van abarcando unos a otros y de manera sucesiva hasta llegar a configurar la totalidad de los cuerpos, la facies totius universi. ${ }^{7}$ Así pues, un cuerpo está necesariamente compuesto al infinito, pues otras partes -que le son extrínsecas - interactúan componiendo cuerpos más complejos que forman, en su totalidad, un universo

6 Spinoza nos ofrece una curiosa teoría de los cuerpos en general en una serie de axiomas, definiciones y postulados que siguen a E2P13.

7 Esta expresión es empleada por Spinoza en la epístola 64 del 29 de julio de 1675 dirigida a Schuller. Véase Baruch de Spinoza: Correspondencia completa, trad., introducción, notas e índices de Juan Domingo Sánchez Estop, Hiperión, Madrid, 1989. 
infinitamente cambiante, el cual expresa la potencia de la Sustancia. Si esos cuerpos llegan a entrar en otra relación, pasan a componer un modo existente distinto, al que le corresponde a su vez otra esencia o grado determinado de potencia. Esta transformación de un modo en otro explica por qué la muerte del cuerpo no es su aniquilación, pues su "materia" compuesta por el movimiento y el reposo pasa a formar parte de un individuo distinto.

Sin embargo, la presión de los cuerpos circundantes es condición necesaria pero no suficiente para que los cuerpos se conserven en la duración como una entidad individuada y no sucumban frente a la presión ejercida por el medio ambiente. Todo individuo, según se mencionó, es un organismo complejo. Dada esta complejidad inherente al individuo, Spinoza menciona (además de ese mecanismo externo de cohesión al que se aludió) un segundo mecanismo, esta vez intrínseco: la subsistencia de esta estructura o compuesto que es el cuerpo individual depende de que éste se conserve como entidad a través de los cambios de las partículas constitutivas o componentes que hacen de él, el individuo que es. Es decir, un individuo, que es un cuerpo compuesto u organismo, requiere para ser tal que las partes que lo componen se comuniquen el movimiento, unas a otras, según una cierta relación constante que se traduzca en un quantum fijo de movimiento o reposo, quantum que se mantiene a través de todos los cambios que afectan a las partes de ese cuerpo.

El individuo, caracterizado hasta el momento como este quantum fijo de potencia, como un complejo homeostático, se define en última instancia por una propiedad de tipo inercial: mientras las relaciones entre sus diversas partes sean constantes, sigue siendo el mismo que era, aun cuando ninguna de esas partes sea la misma parte en sentido significativo. Aquello que define al individuo, por lo tanto, no es un número de predicados posibles, sino esta propiedad funcional de conservar esta forma de movimiento y reposo que constituye una especie de "Gestalt" y ésta no es sino esa determinada ratio o proporción de sus elementos componentes. El individuo es, en definitiva, una resultante homeostática, una unidad orgánica que se configura a partir de la integración de sus componentes simples en dicha Gestalt, fijada tanto en virtud de la presión ejercida por los cuerpos lindantes, como por este mecanismo interno que da lugar a una cierta coherencia en su organización (E2Def. que sigue al Ax.2). Por lo tanto, según se dijo, si reunimos en una única proposición las dos acciones complementarias que caracterizan a un individuo como tal, diremos que el criterio que fija que un individuo, efectivamente, conserva su existencia, es la constatación de una cierta resistencia inherente a su organización o, lo que es lo mismo, de que subsiste como individuo siempre y cuando la presión de los demás cuerpos no lo modifique 
en sus relaciones de movimiento y reposo hasta un punto tal que deje de ser el individuo que era.

En el TIE: $57^{8}$ Spinoza declara que es imposible que alguna cosa pueda modificar su estado sin la intervención de una tercera. En el lenguaje de su física, diríamos que la forma del individuo se conserva indefinidamente, salvo que otro individuo ejerza alguna acción que quiebre su equilibrio. A propósito de esta condición inercial, allí se cita un ejemplo que ilustra precisamente una supuesta clase de eventos imposibles. El filósofo nos invita a hacer un experimento mental: supongamos, dice, una vela que ardiera en un espacio imaginario en donde no existiera ningún otro cuerpo. Esta vela, en sí misma, no contendría nada que pudiera ser causa de su autodestrucción. Y al no haber cuerpos a su alrededor —ni oxígeno siquiera-, estaríamos obligados a suponer que continuará en el estado en el que se encuentra. Hipotéticamente, debería arder indefinidamente, pues la materia, según piensa Spinoza, es absolutamente incapaz de modificar por sí misma su estado. Spinoza declara que afirmar de una vela que está ardiendo, que ya no arde, o que arde en un espacio imaginario o en donde no existe ningún cuerpo, es enunciar distintos eventos que o no pueden tener correlato alguno en la realidad o que son imposibles de contrastar con otra experiencia. En el primer caso, si de una vela que está ardiendo es posible concebir que deja de estarlo, es porque sólo se recuerda otra vela distinta que no arde o, en su defecto, se concibe a la misma vela, pero sin la llama, y se predica de la primera vela la propiedad de arder que constato en la segunda. En el segundo de los casos, cuando se concibe una vela que arde en un espacio imaginario o en donde no existe ningún cuerpo, esto es, cuando se hace abstracción de los cuerpos circundantes y se considera la vela en sí misma, se concluye que la vela no tiene razón para cambiar de estado, o causa que provoque su destrucción. ${ }^{9}$ Si estas condiciones ideales pudieran

8 Spinoza: Tratado de la reforma del entendimiento (TIE). Principios de filosofía de Descartes. Pensamientos metafísicos (CM); introducción, traducción, notas e índices de Atilano Domínguez, Alianza Editorial, Madrid, 1988.

9 Thomas Cook, en "Self-Knowledge as Self Preservation?" (Spinoza and the Sciences, Marjorie Grene y Debra Nails (eds.), Reidel Publishing Company, Dordrecht, 1986, pp. 202 203), observa que este ejemplo tiene los límites de un experimento mental. Es comprensible que, viviendo antes de Lavoisier, Spinoza no haya comprendido el papel del oxígeno en la combustión. Pero sorprende que no haya reconocido que el fuego necesita aceite o algún tipo de combustible para mantenerse. Además, de hecho, una vela que arde es una cosa sobre la que ya actuó un agente externo — quien la encendió- y el hecho de que se consuma ha de explicarse como un efecto de, por ejemplo, un proceso de combustión generado por la acción inicial de ese agente externo. Pese a todo, esta objeción no invalida el ejemplo como tal. Pues lo que le interesa a Spinoza es señalar que, en todos los casos, si no hay modificación autoprovocada (y el ejemplo aspira a ilustrar que no puede haberla), entonces la destrucción de una cosa supone la acción de un agente exterior (E3P8D). 
darse efectivamente en la experiencia, la condición de la vela no variaría, esto es, permanecería ardiendo indefinidamente. ${ }^{10}$ De acuerdo con esta lectura, entonces, esta tendencia a la autoconservación es absoluta, aunque inverificable en la experiencia.

Esta persistencia indefinida de la vela en el estado en que se encuentra prueba por el absurdo la imposibilidad esencial de la autodestrucción (porque la vela persistiría indefinidamente justo porque en ella no puede darse factor alguno que pueda ser causa de su propia descomposición). ${ }^{11}$ Esta imposibilidad se predica de todas las cosas singulares, entre ellas, el hombre. En condiciones ideales, si éste se encontrara en un medio tal que no existieran otros modos que lo afectasen, ese hombre permanecería en la existencia indefinidamente.

\subsection{La doctrina del conatus}

El experimento descrito en el TIE, según notamos, precede e ilumina la doctrina del conatus expuesta en la Ética, según la cual "si fuese posible que el hombre no pudiera padecer otras mutaciones que las que pueden entenderse por la naturaleza del hombre mismo, se seguiría que no podría perecer, sino que necesariamente existiría siempre" (E4P4D).

Esta supuesta perennidad intrínseca a las cosas singulares - la que no tiene sino un valor meramente hipotético-, nos descubre que la cuestión es más compleja de como se la lee sólo a partir de la teoría física a la que Spinoza adhiere y tal como es expuesta en la segunda parte de la Ética, y que ella se ha de interpretar en el marco de su metafísica: la Sustancia es una potencia productora del mundo o Natura naturans, la cual produce los modos singulares. Éstos, a su vez, expresan a la Sustancia, cada uno de ellos según el grado de potencia proveniente de la Sustancia y que constituye su esencia particular. Observa Spinoza: "Las cosas singulares [...] [son] cosas que expresan de cierto y determinado modo la potencia de Dios, por la cual Dios es y obra" (E3P6). Así se comprende que la esencia se defina como una potencia o intensidad que hace que la cosa singular persevere en la existencia (E3P7).Y esto, así lo cree Spinoza, equivale a decir que esta tendencia a perseverar es la expresión finita de la potencia infinita de la Sustancia.

10 Dado que estos casos no tratan de ficciones, sino de puras y simples afirmaciones incontrastables (o que han de ser contrastadas en la experiencia), el mismo Spinoza, en una nota al pie, explica de manera análoga las hipótesis científicas.

11 Es así pues que, según afirmará más tarde Spinoza, en E4P20S, que un hombre quiera acabar con su propia vida - al igual que la vela que, aislada, no se consume- es imposible. Con este argumento Spinoza niega de plano la posibilidad del suicidio. 
Si la esencia real de cualquier cosa particular, en cuanto es una expresión singular de la potencia infinita, es ella misma una tendencia a conservarse, se advierte que una vez examinada la física expuesta en la Ética y en el marco de la Sustancia como potencia productora de todos los modos, se puede afirmar que existe una continuidad entre el rasgo inercial del complejo homeostático, puramente mecánico, y la teoría del conatus, de orden dinámico. ${ }^{12}$ En efecto, esta teoría que condensa el principio de inercia en el plano de la mecánica se expresa asimismo en la metafísica expuesta en la Ética. Allí Spinoza resume su doctrina del conatus declarando que "cada cosa se esfuerza, cuanto está en ella, en perserverar en su ser" (E3P6 y cfr. P7). Esta doctrina responde a su propia teoría de la definición: de acuerdo con dicha teoría, nada que sea incompatible con una cosa puede ser incluido en su concepto o definición. Por ejemplo, ninguna propiedad incompatible con su naturaleza geométrica puede ser incluida en la definición de círculo. De esta manera, Spinoza traduce su doctrina del conatus del plano metafísico al lógico, al declarar que en la esencia de una cosa no puede incluirse una propiedad autodestructiva que contradiga a dicha esencia, dado que ésta es afirmación pura. Esto significa que si la naturaleza intrínseca de la cosa consiste en una cierta proporción de movimiento y reposo, entonces la definición de la cosa excluye toda propiedad que sea incompatible con esa proporción que, en última instancia, la define. Correlativamente, cualquier propiedad o cosa que sea incompatible con la cosa, que de darse, la destruiría, ha de ser concebida como extrínseca y no como parte de su naturaleza intrínseca (E3P4).

Esta teoría física constituye la base conceptual de esta entidad que es el individuo. En efecto, según piensa Spinoza, una de las dimensiones fundamentales de la existencia de los cuerpos en general es la interacción, esto es, su relación con otros cuerpos. Si se traduce este juego puramente mecánico al lenguaje de los modos, se descubre que, paradójicamente, así como mi poder de actuar es mi poder de afectar otros cuerpos, inversamente el poder de actuar de esos otros cuerpos es su poder de actuar, entre otros, sobre mi cuerpo. Esto significa que un cuerpo se ha de definir por el conjunto de relaciones que lo componen o, lo que viene a ser exactamente lo mismo, por su poder de afectar y ser afectado.

12 Véase la defensa de esta posición en André Lecrivain, "Spinoza and Cartesian Mechanics”, en Spinoza and the Sciences, M. Grene y D. Nails (eds.), op. cit., p. 46. Esta cuestión ha sido debatida especialmente en contra de la posición adoptada por Martial Guéroult en Spinoza: L'ame (Éthique, 2), Aubier-Montaigne, París, 1974, quien deslinda la doctrina del conatus de la teoría física de Spinoza. 
Este punto de interacción entre dos cuerpos, declara Spinoza, es un occursus, un encuentro. ${ }^{13}$ En verdad, se producen tanto buenos como malos encuentros. ¿Qué caracteriza a un mal encuentro? Todo mal encuentro se califica como tal porque acontece allí donde un cuerpo se mezcla con otro cuerpo en condiciones tales que peligra la relación que lo configura como individuo. ${ }^{14}$ Estos encuentros, como es notorio, constituyen un riesgo de descomposición y hasta pueden llegar a amenazar la existencia: el grado extremo se alcanza cuando la mezcla con el otro cuerpo disuelve la ratio de movimiento-reposo que define a un individuo como una entidad singular. Pero este proceso de destrucción, tal cual lo expone Spinoza en su física, también es puramente mecánico y le adviene al cuerpo como efecto de una acción ejercida desde afuera: el cuerpo muere, simplemente, cuando sucumbe bajo las presiones del medio.

Estos procesos extrínsecos de destrucción de la cosa singular convalidan el símil de la vela: por una parte, concebir la muerte como un proceso fisiológico autónomo contradice la esencia de todo modo, definido por su esfuerzo en conservar su ser. Por otra, al igual que cualquier cosa singular, inmersa en la duración, ni siquiera el hombre puede sustraerse al influjo de las cosas exteriores, pues no puede no ser parte de la Naturaleza. El destino del cuerpo humano, como el de todo cuerpo, es su destrucción resultante de la actividad de otros cuerpos. Esta descripción resume una de las perspectivas adoptadas por Spinoza para aludir a ese evento que denominamos "muerte".

De todas maneras, esta primera concepción de la muerte se presenta necesariamente sesgada. Pues hasta el momento nos referimos a los seres humanos de forma similar a como hablamos de las cosas del mundo en general (tal vez en un remedo de Spinoza cuando declara que el hombre no es un imperio dentro de otro imperio en E1Ap.). Pero como es notorio, esta aproximación, ciertamente, no agota el ser del hombre. Pues éste no puede

13 "Quoties (mens) ex communi Naturae ordine res percipit, hoc est quoties externe, ex rerum nempe fortuito occursu, determinatur" (E2P29S).

14 Spinoza interpretaría en esta línea el problema del pecado original. Cuando Dios le prohíbe a Adán comer del fruto del árbol del Edén, Dios, reflexiona Spinoza, sólo le está advirtiendo a Adán sobre las consecuencias naturales de la ingestión del fruto: éste lo intoxicará, lo indigestará, lo envenenará, esto es, provocará que las partes del cuerpo de Adán (y la correspondiente idea del fruto lo hará con las ideas que componen el alma de Adán) entren en nuevas relaciones que no se corresponden ya con su esencia (simplemente porque el encuentro de estos dos cuerpos, el de Adán y el del fruto, no se componen, no son combinables). Adán, quien no alcanza a comprender esta advertencia, la interpreta como una prohibición de índole moral. Véase Tractatus theologico-politicus, cap. 4 y la epístola 19 a Blyenbergh. También los excelentes comentarios de G. Deleuze en un volumen reunido con el nombre de Spinoza: Philosophie pratique, París, 1981. Hay versión castellana: Spinoza: filosofía práctica, Tusquets, Barcelona, 1984. 
ser reducido a un conjunto de funciones puramente mecánicas. Ni siquiera es un ser definible en términos exclusivamente orgánicos. Es una clase de individuo que, por una parte desea y, por otra, evita el sufrimiento. Es imaginación y memoria. El hombre es tanto historia como anticipación, no es vida meramente biológica sino vida biográfica. Examinemos, entonces, una segunda perspectiva, la que toma en cuenta esta riqueza inherente al individuo humano.

\section{La muerte biográfica: la muerte como pérdida de la identidad personal}

Se señaló que la definición más precisa que ofrece Spinoza del concepto de muerte es aquella que la enuncia como la destrucción del cuerpo. Se dijo también que nuestro filósofo parte del supuesto de que el cuerpo es una ratio o proporción de movimiento y reposo (E2Lem.1). Ahora bien: ¿̇se puede decir, simplemente, que en un cuerpo vivo todas sus partes se hallan en movimiento; en uno muerto, en reposo? Según parece, Spinoza no dice eso. En primer lugar, este filósofo no podría asentir a un reduccionismo como el mencionado pues, en principio, adhiere a la física cartesiana según la cual el movimiento es el contrario y no el contradictorio del reposo, y ambos se dan conjuntamente en un único modo. Y en segundo lugar, de acuerdo con su concepción homeostática de los cuerpos expuesta en su teoría física, un cuerpo vivo se distingue de un cadáver (como de cualquier otro cuerpo) en la distinta proporción de movimiento y reposo que guardan entre sí las partes que lo componen. De todas maneras, esta respuesta no nos dice demasiado sobre qué cosa es propiamente eso que denominamos "muerte".

Pues si la muerte se define por la destrucción del cuerpo, en palabras del filósofo, "el morir puede ser algo diferente de volverse un cuerpo sin vida" (E4P39S), dado que el cuerpo puede sufrir otras formas de desintegración que no sean las que lo transformen en un cadáver. Esta aproximación, en lugar de tomar en cuenta los procesos biológicos que integran las funciones de un individuo, se sustenta en una explicación "mentalista": Spinoza piensa que la identidad personal, más que por cierta continuidad corporal, se define por la conservación de cierta continuidad psicológica. En el centro de las discusiones contemporáneas sobre el tema, Michael Green y Daniel Wikler, siguiendo esta misma línea argumentativa, sostienen que podemos establecer qué procesos biológicos dan cuenta de la muerte de una persona si investigamos qué es lo que hace a una persona, precisamente una persona, esto es, qué es en ella lo esencial. En pimer lugar, debemos determinar las condiciones en las cuales una persona dada conserva su identidad a lo largo del tiempo, y luego tratar de determinar qué funciones biológicas son necesarias para la conservación de su identidad personal. Recién allí 
estamos en posición de decir que la pérdida irreversible de estas funciones biológicas indican la muerte de esa persona. Según esta interpretación, una persona muere cuando se destruyen los procesos neurológicos que sustentan la continuidad psicológica. Estos procesos neurológicos se localizan en la parte superior del cerebro. Por lo tanto, la destrucción irrerversible de estos procesos es suficiente para la muerte de una persona. ${ }^{15}$

En consonancia con esta formulación del problema, y casi coloquialmente, Spinoza cita el caso de un poeta español del que le hablaron. De acuerdo con la narración que el filósofo trae a cuento, durante su vida lúcida este poeta habría compuesto numerosas comedias y tragedias en su lengua natal. A cierta altura de su vida, el poeta padeció tales mutaciones que uno "no diría fácilmente de él que es el mismo". ${ }^{16}$ Hoy diríamos del poeta que sufrió amnesia o, tal vez, que sufrió un ataque de isquemia cerebral o padece el mal de Alzheimer.

El poeta conservaría sus funciones metabólicas intactas, habiendo perdido el sentido de continuidad temporal que le permitiría reconocerse a sí mismo como el autor de sus obras. Ahora bien: una vez admitida la doctrina del paralelismo de los atributos, según la cual a toda modificación en el plano de la Extensión le ha de corresponder una modificación correlativa en el plano del Pensamiento (y viceversa), ¿acaso esta cita no lo desmiente? Examinemos, por un momento, la fisiología supuesta por este caso que presenta una aparente disociación psicofísica.

De acuerdo con la doctrina del paralelismo, la imaginación pertenece a la esfera del Pensamiento: ella nos representa los cuerpos externos como presentes ante nosotros (E2P17S). Por su parte, la memoria expresa en la esfera del pensar el hecho fisiológico de que el cuerpo no olvida nada, dado que conserva para siempre el trazo material (vestigium) del choque de otros cuerpos sobre ciertas partes de sí mismo. Esto significa que mientras el cuerpo preserva una determinada ratio de movimiento y reposo, el individuo conserva los trazos dejados por el choque de los otros cuerpos sobre su superficie. Pero así como la imaginación es una afección del alma, la imagen, en cambio, es extensional. En efecto, la imagen, piensa Spinoza, es una afección, y pese a la connotación mental que en nuestros días este término evoca, Spinoza afirma que se trata de una impresión corpórea -aunque distinta del simple trazo material (vestigium)—, que se produce cuando el cuerpo es afectado por otros cuerpos.

15 M.B. Green y D. Wikler, "Brain Death and Personal Identity", en M. Cohen, T. Nagel y T. Scanlon, Medicine and Moral Philosophy, Princeton University Press, Princeton, 1981, pp. 4977.

16 Este ejemplo sólo es citado en E4P39S. 
Esta correlación entre las facultades del alma y la existencia actual del cuerpo que constituye su ideatum es confirmada por Spinoza cuando declara que "la potencia del alma por la cual imagina las cosas y se acuerda de ellas, depende [...] de que el alma implica la existencia actual del cuerpo" (E3P11S). Pero una vez que se pierde la proporción que lo determinaba como un individuo en particular (el poeta español sufrió cambios cerebrales que desintegraron dicha proporción), también se pierden las imágenes y los recuerdos. El cambio corporal, resultante de la adquisición de una nueva proporción de movimiento y reposo, implica —en el caso del poeta español- la extinción de estos trazos de la memoria (E2P17CD). ${ }^{17}$ En suma, el cuerpo, objeto del alma, es condición sine qua non de la persistencia de la actividad de la imaginación y de la memoria. Sin embargo, se puede perder dicha actividad anímica aun cuando el cuerpo se conserve.

Si la identidad personal radica en el ejercicio de ciertas facultades, se infiere que la memoria, si bien es condición necesaria de la personalidad y hasta fija el criterio de identidad personal, al depender de la actividad de la imaginación (y, por ende, de las cosas singulares que la afectan), perece con el cuerpo (E3P11S, E5P21). El caso del poeta español nos enseña entonces que, aun cuando las funciones metabólicas persistan, el individuo puede alterar su personalidad hasta alcanzar cierto grado en que deja de ser el individuo que fue, esto es, pierde su identidad. La muerte tendría lugar, de acuerdo con este criterio de identidad personal, cuando se produce una discontinuidad en dicha identidad. ${ }^{18}$

El poeta, según el criterio de Spinoza, aunque siguiera respirando, con circulación sanguínea y hablando español y, en consecuencia, no fuese un cadáver, sin embargo estaba muerto. Esto es lo mismo que decir que si el cuerpo adquiere otra naturaleza, es porque está muerto, independientemente de si sus funciones metabólicas siguen en actividad o no. Y cuando Spinoza afirma que "ninguna razón me obliga a admitir que el cuerpo no muere sino cuando se muda en cadáver" (E4P39S), está reconociendo que, aunque subsistan ciertas funciones vitales, se puede considerar a ese individuo muerto. Pues bien: ¿cómo se concilia esta aparente disociación psicofísica con la doctrina del paralelismo? El paralelismo, piensa Spinoza, no es un obstáculo, porque al fin y al cabo el cuerpo es el alma y el alma es el cuerpo. Por lo tanto, si se da una discontinuidad mental, debe darse

17 Esta tesis, en apariencia difícil de conciliar con el paralelismo, sería absolutamente plausible si suponemos, según se ha llegado a interpretar, que el criterio de identificación de individuos se aplica a cuerpos en el espacio y que toda identidad mental es derivada. Véase Lee C. Rice, "Spinoza on Individuation", en Eugene Freeman y M. Mandelbaum (eds.), Spinoza: Essays In Interpretation, Open Court, La Salle, Illinois, 1975, pp. 210-211.

18 Wallace Matson, "Death and Destruction in Spinoza's Ethics", Inquiry, no. 20, 1977, pp. 403-417. 
asimismo necesariamente cierta discontinuidad corporal (o a la inversa, dado este paralelismo). Pero dicha discontinuidad puede afectar a determinadas facultades del individuo, y no necesariamente a la totalidad. Y la calidad de vivo o muerto puede predicarse a partir del ejercicio o no de dichas facultades. Si nos referimos a una "aparente" disociación psicofísica es porque dicha disociación se predica sólo si consideramos al individuo una entidad autosuficiente. En cambio, si se observa que éste forma parte de la facies totius universi, se advierte inmediatamente que el resto del individuo, considerado extensionalmente, esto es, en cuanto a su materia compuesta por el movimiento y el reposo, pasa a formar parte de otros individuos distintos.

El poeta, volviendo a la narración del filósofo, habría cambiado su naturaleza: en su primera versión, al poeta se le adscribían las propiedades $r$ y $s$ (compuso comedias y tragedias, y hablaba español); en la versión modificada del poeta, la propiedad $r$ ya no formaba parte de su naturaleza, pues olvidó que había compuesto esas obras dramáticas. Lo que define al poeta son las propiedades que lo caracterizaban como ese individuo particular. Spinoza piensa que la facultad de la imaginación es el lugar de origen de nociones como son los universales. Éstos se forman cuando la cantidad de imágenes supera la capacidad del alma para captarlas de modo distinto, se confunden todas entre sí (E2P40S1). Este nominalismo a ultranza lleva a Spinoza a sostener que el concepto de hombre, en cuanto universal, es un producto de la imaginación. Un conocimiento superior capta al hombre en su particularidad (Pedro con sus propiedades singulares y Pablo con las suyas propias). Alejándose de todo esencialismo de clase, así Spinoza coincide con M. Green y D. Wikler en otro punto más: ${ }^{19}$ polemizando con Robert Veatch, quien declara que si se intenta definir la muerte de un ser humano, "debemos reconocer las características esenciales a la humanidad [...] Usamos el término muerte para significar la pérdida de lo que es esencialmente significativo para una entidad, en el caso del hombre, la pérdida de humanidad", ${ }^{20}$ estos autores niegan que haya que establecer qué clase de cosas son las personas, en términos de sus propiedades esenciales, pues una investigación de este orden desembocaría en una teoría esencialista de clase (fundada en una presunta nota esencial compartida por los miembros de la clase "persona"). En su lugar, estos autores proponen un esencialismo individual, dado que nuestras intuiciones acerca de las condiciones que conservan la identidad personal son más claras y consensuadas que nuestras intuiciones sobre las condiciones de la personalidad en general.

19 Op. cit., p. 62 , nota 26 y p. 63 , nota 28.

20 Death, Dying and the Biological Revolution, p. 26, citado por Green y Wikler, op. cit., p. 63. 
Este esencialismo individual anticipado por el filósofo expresa el rasgo que define el estar vivo o muerto, por lo menos en lo que concierne a estos individuos muy organizados que son los hombres. Dicho rasgo no es la capacidad para una vida biológica (esto es, la actividad de las funciones metabólicas comunes a todos los seres vivos) sino la realidad de una vida biográfica (esto es, el ejercicio de una actividad racional, enriquecida por nuestras vivencias, o sea, por las imágenes y los recuerdos experimentados).

En lo que sigue, observaremos que esta aparente disociación psicofísica es absolutamente consistente con el sistema del filósofo: pues si el alma se redujera a los procesos padecidos por el cuerpo, ¿qué sería de la eternidad del alma, esa eternidad que anima toda la empresa spinoziana? Con este interrogante, nos aproximamos a la tercera y última de las perspectivas spinozianas acerca de la muerte.

\section{La negación de la muerte sub specie aeternitatis}

Esta última perspectiva nos obliga a abandonar el lenguaje de la ciencia y, en su lugar, a internarnos en el nudo de la metafísica de Spinoza. Al empezar, se dijo que Spinoza declara que "se quita la existencia presente del alma y su potencia de imaginar tan pronto como el alma deja de afirmar la existencia presente del cuerpo" (E3P11S), esto es, el alma abandona la existencia presente cuando deja de afirmar la existencia presente del cuerpo. Se puede objetar que una muerte del alma concomitante con la del cuerpo, tal como parece sugerir este pasaje, suscita más de un problema. Por una parte, que el alma cese de ser el correlato de un cuerpo cuando ya no lo afirma como existente confirma la actividad de la imaginación y de la memoria como los correlatos no extensionales de las afecciones corpóreas. Sin embargo, por otra parte, parece contradecir el análisis del poeta español, pues ¿cómo se explica entonces que el cuerpo persista en sus funciones metabólicas y el alma ya no lo afirme a través de actos ligados con la conciencia, como efectivamente son los de la imaginación y la memoria? Pareciera, entonces, que no es tan sencillo conciliar el paralelismo según el cual cuando muere el cuerpo, el alma cesa en sus funciones, con la mención del poeta español muerto, pero desvariando.

Pues bien, si el cuerpo puede conservar sus funciones metabólicas independientemente de la actividad del alma se debe simplemente a que el alma, lisa y llanamente, no es idéntica a la conjunción de la imaginación y la memoria constitutivas de una conciencia personal. Porque el alma implica cierta conciencia, pero no es toda ella conciencia: así como el cuerpo está compuesto de un gran número de cuerpos, el alma se halla compuesta de un gran número de ideas representativas y modos de pensar no representativos (esto es, entre otros, los afectos, como el amor y el odio; ficciones como el 
hipogrifo o ciertas creencias; los seres de razón, como el número, el tiempo, la medida). Sin embargo, eso no significa que todas las ideas y los modos se den en el nivel de la conciencia. La extensión de nuestra alma sobrepasa indefinidamente el ámbito de nuestros pensamientos conscientes, y en el sistema de Spinoza, ha de ser necesariamente así. ${ }^{21}$

De esta manera se explica que, según cree Spinoza, hay algo en el alma que se sustrae a la determinación de las cosas particulares, o lo que es lo mismo, a la cadena temporal de causas y efectos: una parte del alma que no se halla sometida al influjo de la imaginación y, por ende, de la memoria, se libera del influjo de la duración y subsiste eternamente como idea en el entendimiento o intelecto de Dios (idea Dei).

Precipitadamente, se puede llegar a interpretar esta subsistencia del alma como una nueva versión de aquellos prejuicios que el propio Spinoza, a modo de declaración programática, se propuso esclarecer, ficciones tales como que existe una finalidad en la naturaleza o, en el ámbito de lo humano, algo así como una libertad de la voluntad (E1Ap.). Sin embargo, no es justo atribuirle esta inconsistencia. Cuando nuestro filósofo procura fundamentar esta doctrina, lo hace con una explicación distante no sólo de la teología -donde la afirmación de un Dios personal y providencial condiciona cualquier contenido doctrinario-, sino también de las concepciones filosóficas de sus antecesores: en el modelo aristotélico, el alma es una fuerza no corpórea que anima al cuerpo, independiente de las reacciones químicas y de la circulación de fluidos que garantizan el normal funcionamiento del organismo. De acuerdo con este modelo, la circulación de fluidos cesa cuando el alma abandona el cuerpo, y cesa porque, precisamente, el alma ya no lo anima. En el modelo cartesiano, en cambio, no se admite el anima —ni la vegetativa ni la motriz - como principio que anima el cuerpo. Pues al igual que un muñeco de cuerda puramente mecánico, cuando las partes que integran el cuerpo se malogran, entonces el cuerpo deja de funcionar. El alma, alojada en un navío que ya no le sirve, entonces lo abandona. ${ }^{22}$

A diferencia de los filósofos mencionados, Spinoza sostiene que la causa de que el alma deje de afirmar la existencia del cuerpo no puede ser el alma misma, pues, por la doctrina del paralelismo, la tendencia a perseverar del

21 Guillermo de Blyenbergh (epístola 24 del 13 de marzo de 1665) le señala a Spinoza que si el alma es un compuesto de miles de pensamientos, tras la muerte del individuo, el alma se desintegra tanto como se desintegra el cuerpo. Pero Blyenbergh no advierte que el alma (como así también el cuerpo) posee una esencia que forma parte de la potencia de la Sustancia, de una naturaleza distinta de la de sus partes componentes (en este caso, las ideas y los modos de pensar en general).

22 Agradezco a la profesora Laura Benítez, quien, en un congreso, me señaló este punto de un modo tan didáctico e ilustrativo. 
cuerpo y la tendencia a comprender del alma, son una y la misma tendencia considerada ya bajo el atributo de la Extensión, ya bajo el del Pensamiento.

Pareciera que comprender esta aproximación que rescata de la muerte a cierta parte del alma, supone volvernos nuevamente a la Sustancia. Observemos que, por el determinismo, en ella todas las cosas son necesarias. Mientras que la Sustancia lo es por su propia esencia o naturaleza, todo lo demás (entre otras cosas, ese modo singular que es el hombre) lo es pues se halla determinado, en cuanto a su esencia o naturaleza, por la causalidad inmanente de la Sustancia, y en lo que concierne a su existencia, por otras causas singulares (en el caso de un hombre particular, sus padres y toda la cadena de sus ancestros).

Así como las existencias (tanto las psíquicas como las corporales) constituyen un orden de causas reales, según el cual se encadenan las unas a las otras (las psíquicas determinan a las psíquicas, las corporales a las de su orden correspondiente); las esencias, por su parte, también constituyen un orden de causas reales. Sin embargo, ha de advertirse que, a diferencia del orden de las existencias, una esencia singular no causa otra esencia singular. Una esencia singular adviene a la existencia - tal como explicábamos a propósito de la formación de los cuerpos- por leyes puramente mecánicas que determinan una infinidad de partes extensivas de manera tal que éstas llegan a constituir una forma particular, expresándose la esencia de esa cosa singular en dicha forma. Una vez que la cosa singular ha ingresado en la existencia y, en la medida en que las causas exteriores no destruyan esa fuerza interna que es su conatus, esa cosa singular persevera naturalmente en la existencia. Ese perseverar puede continuar indefinidamente pues el conatus procede metafísicamente de la potencia divina. Más aún: el conatus es esta potencia divina en cuanto ella se expresa en la esencia de la cosa singular. Y por su procedencia, esta esencia (como lo ilustró el ejemplo de la vela) es eterna.

Por el momento, según parece, aun cuando se afirme que las existencias son efímeras - porque dependen de la acción de los cuerpos exteriores- y las esencias son eternas - porque proceden de la Sustancia-, no termina de comprenderse cómo se concilia la destrucción de las existencias y la supervivencia de las esencias. Esta conciliación se vuelve aún más compleja cuando además se considera que las esencias de las cosas individuales son, ellas también, individuales. En el TIE:17, Spinoza declara que entre la esencia de una cosa y la de otra existe la misma diferencia que se da entre la existencia de la primera y la existencia de la segunda.

Pues bien, ¿cómo se concilia esta escisión entre la temporalidad de las existencias y la eternidad de las esencias con la doctrina del paralelismo? En el plano de las existencias, el alma es un modo condicionado por los 
otros modos. La existencia del cuerpo individual es inseparable de la del alma, pues es su ideatum. Se observó que el alma de un cuerpo existente se caracteriza por la posesión de poderes propios de la imaginación y de la memoria que operan a partir de las sensaciones. El alma se esfuerza por imaginar todo aquello que acrecienta su potencia de actuar (E2P59). En algún momento, según se dijo, el cuerpo junto con el alma que es su correlato, debido a la presión ejercida por los cuerpos circundantes, cede a dicha presión, destruyéndose su quantum fijo de movimiento y reposo que lo mantuvo en la existencia. Así se comprende que, una vez que en el individuo se rompe esa constitución esencial, el cuerpo muere. Cuando su existencia cesa, estos poderes del alma también cesan de existir, pues el alma sólo puede imaginar o recordar algo mientras el cuerpo dure, mientras se mantenga en la existencia, pues estos poderes operan siempre y cuando haya sensaciones (E5P21). Pero ésta es una descripción parcial del alma.

Tal vez esta conciliación sea más fácil de aprehender si nos volvemos hacia el alma en su calidad de entidad compleja. Retornemos una vez más a la segunda parte de la Ética y en especial a E2P7S, donde Spinoza introduce esta tan mentada doctrina que más tarde Leibniz denominará "paralelismo". Sabemos que el alma es una idea (y de algo realmente existente: el cuerpo). Y en esta idea, como en toda idea, Spinoza concede que se pueden distinguir conceptualmente tres aspectos:

a) Considerada en su realidad objetiva, el alma es la afirmación de la existencia real de su objeto (el cuerpo humano). Si el alma pudiera formarse una idea de la muerte como resultante de un mal encuentro que menoscaba la potencia de un individuo, en ese caso el alma tendría ideas adecuadas de algo que se hallaría en abierta contradicción con la esencia de toda cosa - su tendencia a perseverar en el sery esto no es posible. Ésta es una de las razones por las cuales, según mencionamos, no puede haber una idea verdadera, positiva o propiamente dicha de muerte. Esta limitación concierne al alma considerada como totalidad. Pero en el alma se pueden discernir dos partes: una vinculada a la eternidad; otra, a la duración.

En la medida en que forma parte de una cadena de cosas sujetas a la duración, el alma con sus actividades centradas en la memoria y en la imaginación también depende de la existencia del cuerpo. De manera que, y hasta donde podemos hablar de una muerte del alma, "se quita la existencia presente del alma y su potencia de imaginar tan pronto como el alma deja de afirmar la existencia presente del cuerpo". (E3P11S). Por consiguiente, a la idea (que constituye la esencia del alma de un cuerpo) le corresponde como contrapartida extensional, 
la existencia del cuerpo durante el tiempo que exista el cuerpo mismo (E2P17S).

b) Considerada en su realidad formal, el alma como idea subsiste durante todo el tiempo que su objeto se conserve, esto es, en la medida en que sigue siendo la idea de una cosa singular comprendida en los atributos de Dios. ${ }^{23}$

No obstante, de acuerdo con la doctrina del paralelismo, si una causa debe tener algo en común con el efecto (E1Ax.5), la causa de que el alma (que no es sino la idea de un cuerpo) deje de afirmar a ese cuerpo en la duración, nace de otra idea, que excluye a nuestro cuerpo y, por el paralelismo, a nuestra alma y que, por consiguiente, es contraria a la idea que constituye nuestra alma. En otras palabras: el alma (en el aspecto en que depende de las afecciones producidas por los otros cuerpos sobre el cuerpo del que ella es idea, y se halla vinculada, por lo tanto, a representaciones de la imaginación y de la memoria) deja de existir cuando deja de afirmar la existencia del cuerpo, y lo hace debido a una idea que excluye la existencia del cuerpo y, por la doctrina del paralelismo, excluye también la existencia de nuestra alma (E3P11S). Así el alma acompaña —en lo que respecta, al menos, a las cosas propias de nuestro universo espacio-temporala la destrucción del cuerpo, si bien no es la causa de esta destrucción.

c) Considerada en su forma o naturaleza, por lo tanto, el alma es idea de la idea, pues la idea de la idea no es otra cosa que la forma de la idea (E2P21S). O sea, es la idea considerada como conocimiento y, en este carácter, saber del saber, pues saber es saber que se sabe (TIE:27). En su calidad de idea, hay una parte del alma que se encuentra centrada en la memoria y en la imaginación, pero otra parte de ella se sustrae a dichas actividades y percibe solamente ideas adecuadas.

Esta última distinción, precisamente, es la clave que permite explicar la escisión mencionada: la muerte del alma es su destrucción, hecha la salvedad de que dicha muerte no es absoluta sino que concierne a la parte de la misma que está sujeta a la duración. Esto es, la autopreservación, en lo que concierne al alma fuera de la duración, es la conservación del entendimiento (que no abarca ni la preservación de la imaginación ni la de la memoria, las que no son sino un encadenamiento de ideas que refleja las afecciones del cuerpo mientras éste dura).

El alma humana, además de idea del cuerpo, es ella misma idea de una cosa realmente existente en el entendimiento o intelecto divino o idea Dei:

23 Véase sobre este asunto, Henry E. Allison, Benedict de Spinoza: An Introduction, edición revisada, Yale University Press, New Haven, 1987, p. 93. 
aunque el cuerpo haya cesado de existir en la duración, persiste idealmente, pues en Dios se da una idea que expresa la esencia de un cuerpo particular (E5P22). En el KV, Spinoza declara que "como ella (el alma) es un modo en la sustancia pensante, también ha podido conocer y amar a ésta, junto con la de la extensión, y uniéndose con sustancias que son siempre las mismas, ha podido hacerse a sí misma eterna". ${ }^{24}$

El problema suscitado por esta concepción de la eternidad, tal como parece retratarla Spinoza, es que la idea que tiene Dios de nuestro cuerpo, existente o no, no puede constituir nuestra alma en cuanto conciencia individual, ya que nuestra conciencia no es la conciencia de Dios (que tiene Dios de nuestro cuerpo) ni parte de ella. Se ha interpretado entonces que si tras la muerte de nuestro cuerpo actual, sólo quedara la esencia de éste y la idea que Dios tiene del mismo, no habría inmortalidad (eternidad) personal. ${ }^{25}$

Pareciera no obstante que, cuando Spinoza declara que nos sentimos y conocemos como eternos, lo que quiere decir es que conocemos que conocemos, y conocer es aspirar a formar parte del sistema completo de conocimiento que es el entendimiento divino, de manera tal que ser eternos es ser conscientes de nosotros mismos como formando parte de dicho enten-

24 Segunda parte, Prefacio, nota 1: 15, en op. cit., p. 100.

25 En esta objeción se centra la crítica de Miguel de Unamuno a Spinoza. Según Unamuno, Spinoza es un ateo, porque su Dios no es compatible con la conciencia individual y eterna del "hombre de carne y hueso" (véanse los capítulos 1, 2, 3, 5, 9 y 10 de Del sentimiento trágico de la vida, Losada, Buenos Aires, 1998). Frente a la acusación de Unamuno a Spinoza de contentarse con una eternidad abstracta, Joseph Moreau afirma del filósofo español que éste no supo ver en la filosofía de Spinoza aquellos elementos que pudieron haberle suministrado el fundamento metafísico de su esperanza en la inmortalidad personal. Leiser Madanes (en "Moral y muerte: examen de algunas referencias de Unamuno a Spinoza", en La ética de Spinoza. Fundamentos y significados, Actas del Congreso Internacional, Almagro, 24-26 de octubre 1990, Atilano Domínguez (comp.), La Mancha, edición de la Universidad de Castilla-La Mancha, pp. 456-460) cita el artículo de Moreau, "Spinoza et Unamuno", aparecido en Revue de l'enseignement philosophique, año 33, no. 1, octubre-noviembre 1982, pp. 3-10, donde, a juicio de J. Moreau, Unamuno no descubrió en las últimas páginas de la Ética la concepción concreta de la eternidad de nuestra alma. A propósito de esta interpretación de J. Moreau acerca de Unamuno, L. Madanes comenta que "su error [el de Unamuno] consistió en creer que, al excluir el recuerdo de la existencia empírica, la eternidad spinozista abolía la supervivencia del individuo. Moreau interpreta que esto no es así, pues la individualidad no depende de las circunstancias de espacio y tiempo, sino que se funda en la esencia eterna de cada ser singular [...] Las cosas singulares se realizan en dos niveles: el de la existencia espacio-temporal y el de la eternidad de las esencias que están en el entendimiento divino (E5P29Esc.). En este nivel superior, que es el del entendimiento puro, contrariamente a la interpretación admitida por Unamuno, la individualidad no queda abolida. Por el contrario, es en este nivel donde se funda la individualidad y los seres pensantes, las almas singulares, se constituyen cada uno en su esencia como modos infinitos de la sustancia considerada bajo el atributo del pensamiento [...] Esta idea que Dios tiene eternamente de cada uno de nosotros, no es una representación, esto es, una entidad distinta de nosotros. Esta idea somos nosotros" (p. 457). 
dimiento, reconociéndonos integrantes de ese universo de esencias. ${ }^{26}$ Como idea en Dios, el alma forma parte de las cosas sub specie aeternitatis y subsiste eternamente. Si bien esta eternidad del modo es derivada, es un efecto necesario de una causa existente por sí necesariamente, infinita e inmutable.

Así pues, es notorio que, una vez que se captan las cosas inmersas en la duración por medio de ideas adecuadas provenientes del entendimiento, la muerte entendida como alteración cuantitativa es absorbida por la conservación del alma como parte del entendimiento de Dios. La muerte, entonces, sólo puede ser pensada adecuadamente desde esta última perspectiva, pues "nuestra alma, en cuanto implica la esencia del cuerpo bajo la especie de la eternidad, es eterna" (E5P23S). Aunque el poeta español no recordara sus comedias y tragedias, desde la óptica de la eternidad, según parece, ellas son ideas eternas en la mente de Dios.

\section{LA MUERTE COMO PENSAMIENTO IMPOSIBLE}

Pese a que Spinoza declama que "el hombre libre en ninguna cosa piensa menos que en la muerte" (E4P67), constatamos que este tema aparece, desordenadamente, cerca de dos docenas de veces en la Ética. ¿Cómo explicarnos, entonces, las distintas aproximaciones del filósofo a esta cuestión?

Una de las posibles respuestas la podríamos inferir de una cita de Spinoza tomada de su epistolario. El destinatario de su carta le había solicitado a nuestro filósofo que le ilustrase, a través de un ejemplo, cómo puede ser que a una y misma cosa se le atribuyan dos nombres distintos. En especial, no podía explicarse cómo puede ser que dos atributos - el Pensamiento y la Extensión-, que se conciben como diferentes y que, además, reciben diferentes nombres, expresen no obstante una única Sustancia. En su respuesta, Spinoza recurre a un ejemplo procedente del Antiguo Testamento. El nombre "Israel", recuerda, es empleado para hacer referencia a un individuo, pero en otros textos al mismo individuo se lo llama con un nombre diferente, "Jacob", en relación con su hermano. Y, sin embargo, los dos nombres designan a la misma persona, el tercero de los Patriarcas. ${ }^{27}$ Spinoza parece querer decirnos lo siguiente: el hecho de que existan dos denominaciones no nos obliga a suponer que hay dos sustancias separadas (cada uno de los atributos), tal como pensaba Descartes, misteriosamente unidas. Al contrario, existe un único sujeto del cual se predican atributos diferentes, de manera que —en el ejemplo mencionado — todo lo que es verdadero

26 Véase Ruth L. Saw, "Personal Identity in Spinoza", en Studies in Spinoza: Critical and Interpretative Essays, 2a. ed., P. Kashap (ed.), University of California Press, Berkeley/Los Ángeles/Londres, 1974, pp. 86-100.

27 Epístola 9 dirigida a Simón de Vries, de fines de febrero de 1663. 
de Jacob lo es de Israel, y viceversa. Lo central es que se trata de explicar una entidad única, por más que se la describa de diferentes modos. Hay dos conjuntos de descripciones, pero sólo un conjunto de hechos. ${ }^{28}$ Algo semejante acontece con el concepto de muerte, tal como es tratado por Spinoza: distintas descripciones abordan una presunta entidad única. No obstante, cabe señalar que, en el caso de la muerte, tal vez sea más apropiado hablar de una no-entidad: mientras la realidad formal de la noción de muerte es afirmación, la realidad objetiva es su negación. Se comprende entonces por qué, según decíamos, carecemos de una idea propiamente dicha de la muerte. No obstante ante la imposibilidad de pensar la muerte adecuadamente, Spinoza tal vez intentó aproximarse a ella para, de alguna manera, apresarla aunque sea imperfectamente.

En su intento de esbozar una explicación racional que sustituyera la imaginería y la superstición, Spinoza traicionó, tal vez, su declaración de principios, su "homo liber de nullâ re minùs, quàm de morte cogitat" (E4P67), ${ }^{29}$ volviendo una y otra vez al tema de la muerte. Quizás allí radique la razón de que Spinoza, a partir de sus diversas aproximaciones al concepto de muerte, tácitamente nos haya dejado, a manera de legado, esta tarea de clarificación que acabamos de emprender.

BIBLIOGRAFÍA

BiBLIOGRAFÍA PRIMARIA:

Spinoza, Baruch de, Tratado breve (KV), traducción, prólogo y notas de Atilano Domínguez, Alianza, Madrid, 1990.

_- Tratado de la reforma del entendimiento (TIE).

—_, Principios de filosofía de Descartes. Pensamientos metafísicos (CM); introducción, traducción, notas e índices de Atilano Domínguez, Alianza Editorial, Madrid, 1988.

_- Ética demostrada según el orden geométrico (E), traducción de Oscar Cohan, Fondo de Cultura Económica, México-Buenos Aires, 1977.

_- Correspondencia completa, traducción, introducción, notas e índices de Juan Domingo Sánchez Estop, Hiperión, Madrid, 1989.

28 Por ejemplo, las actuales teorías atributivas de la mente afirman que cuando digo "S experimenta dolor", me estoy refiriendo, por medio de una descripción mentalista o psicológica, a los mismos acontecimientos a los cuales podía referirme también utilizando una descripción fisiológica del funcionamiento del cerebro de $\mathrm{S}$.

29 "El hombre libre en ninguna cosa piensa menos que en la muerte." 
BiBLIOGRAFÍA SECUNDARIA:

"A Definition of Irreversible Coma: Report of the Ad Hoc Committee of the Harvard Medical School to Examine the Definition of Brain Death", JAMA, agosto 5, 1968, vol. 205, no. 6, pp. 337-340. Reimpreso en Urovsky, Melvin I. y Philip E. Urovsky (comps.), The Right to Die: Definitions and Moral Perspectives, Garland Publishing, Nueva York/Londres, 1996.

Allison, Henry E., Benedict de Spinoza: An Introduction, edición revisada, Yale University Press, New Haven, 1987.

Bennett, Jonathan, A Study of Spinoza's Ethics, Hackett, Indianápolis, 1984 [versión castellana: traducción de José Antonio Robles García, Un estudio de la ética de Spinoza, Fondo de Cultura Económica, México, 1990].

Cohen, E. Diana, "La mirada del gusano y el ojo de Dios: consideraciones acerca de los principios de individuación y de continuidad temporal en Spinoza", en L. Benítez y J.A. Robles (coords.), Materia, espacio y tiempo: de la filosofía natural a la física, Facultad de Filosofía y Letras, División de Estudios de PosgradoUniversidad Nacional Autónoma de México, México, 1999, pp. 81-94.

Cook, Thomas, "Self-Knowledge as Self Preservation?", en Marjorie Grene y Debra Nails (eds.), Spinoza and the Sciences, Reidel Publishing Company, Dordrecht, 1986, pp. 191-210.

Deleuze, Gilles, Spinoza: Philosophie Pratique, Presse Universitaire de France, París, 1970 (ahora en Editions de Minuit, modificada y aumentada, 1981; versión castellana: Spinoza: filosofía práctica, Tusquets, Barcelona, 1984).

Guéroult, Martial, Spinoza: L'âme (Éthique, 2), Aubier-Montaigne, París, 1974.

Lamb, David, Death, Brain Death and Ethics, Croom Helm, Londres, 1985.

Lecrivain, André, "Spinoza and Cartesian Mechanics", en Grene, Marjorie y Nails, Debra (eds.), Spinoza and the Sciences, Reidel Publishing Company, Dordrecht, 1986, pp. 15-60.

Madanes, Leiser, "Moral y muerte: examen de algunas referencias de Unamuno a Spinoza", en Atilano Domínguez (comp), La ética de Spinoza. Fundamentos y significados, Actas del Congreso Internacional, Almagro, 24-26 de octubre 1990, pp. 445-464, Universidad de Castilla-La Mancha, La Mancha.

Rice, Lee C., "Spinoza on Individuation", en Eugene Freeman y M. Mandelbaum (eds.), Spinoza: Essays In Interpretation, Open Court, La Salle, Illinois, 1975, pp. 195-214.

Savan, David, "Spinoza and Language", en Marjorie Grene (ed.), Spinoza: A Collection of Critical Essays, University of Notre Dame Press, Notre Dame-Indiana, 1979, pp. 60-72.

Saw, Ruth, "Personal Identity in Spinoza", en S. Paul Kashap (ed.), Studies in Spinoza: Critical and Interpretative Essays, University of California Press, Berkeley/Los Ángeles/Londres, 1974, pp. 86-100. 